\title{
Parenting in Battered Women: The Effects of Domestic Violence on Women and Their Children
}

\author{
Alytia A. Levendosky ${ }^{1,3}$ and Sandra A. Graham-Bermann ${ }^{2}$
}

\begin{abstract}
This study integrates an ecological perspective and trauma theory in proposing a model of the effects of domestic violence on women's parenting and children's adjustment. One hundred and twenty women and their children between the ages of 7 and 12 participated. Results supported an ecological model of the impact of domestic violence on women and children. The model predicted $40 \%$ of the variance in children's adjustment, $8 \%$ of parenting style, $43 \%$ of maternal psychological functioning, and $23 \%$ of marital satisfaction, using environmental factors such as social support, negative life events, and maternal history of child abuse. Overall, results support the ecological framework and trauma theory in understanding the effects of domestic violence on women and children. Rather than focusing on internal pathology, behavior is seen to exist on a continuum influenced heavily by the context in which the person is developing.
\end{abstract}

KEY WORDS: domestic violence; child abuse; battered women; parenting; children.

\section{INTRODUCTION}

Research on the psychological effects of domestic violence on women and children extensively documents the harm such violence causes. Battered women experience increased levels of depression, lower self-esteem, and

\footnotetext{
${ }^{1}$ Department of Psychology, Michigan State University, East Lansing, Michigan.

${ }^{2}$ Department of Psychology, University of Michigan, Ann Arbor, Michigan.

${ }^{3}$ To whom correspondence should be addressed at Department of Psychology, 129 Psychology Research Building, Michigan State University, East Lansing, Michigan 48824; e-mail: levendo1@pilot.msu.edu.
} 
higher levels of psychological distress when compared with nonbattered women (Cascardi and O'Leary, 1992; Khan et al., 1993; Rounsaville and Lifton, 1983; Sato and Heiby, 1992; Testa et al., 1993). The severity of physical abuse has been shown to predict levels of depression in battered women (Campbell et al., 1997). In addition, prevalence of posttraumatic stress disorder (PTSD) in battered women is high, ranging from $45 \%$ to 84\% (Houskamp \& Foy, 1991; Kemp et al., 1991, 1995; Vitanza et al., 1995).

Herman (1992a,b) focused on the traumatizing aspects of violence and trauma symptoms exhibited by battered women. She theorized that many battered women suffer from a complex traumatic syndrome that is similar to the diagnos is of PTSD (American Psychiatric Association [APA], 1994), but includes additional symptoms, including depression, anxiety, idealization of the perpetrator, and dissociation, due to the chronic nature of the trauma. Thus, this conceptualization of trauma argues for a much broader understanding of traumatic symptoms than the $D S M-I V$, suggesting that all aspects of psychological distress seen in trauma survivors are part of a trauma syndrome.

Herman (1992a,b) also describes the dynamics of the abusive situation. While suggesting that battered women suffer characterological changes in personality (which leave them vulnerable to repeated harm), she emphasized the perpetrator's actions rather than the woman's premorbid psychological functioning as the reasons for these changes. She argued that, typically, the perpetrator gains control over the woman's body through deprivation of sleep, food, or shelter. He then becomes the potential source of solace when he grants small indulgences. Herman (1992a) reported that this dynamic greatly diminishes the woman's ability to initiate action. The woman's traumatic reaction to the physical and psychological abuse may be the mechanism through which many aspects of the battered woman's functioning may become impaired. Herman argues that strong social support can protect women's functioning in traumatic situations. She also argues that a history of abuse from childhood may make women more psychologically vulnerable.

In addition to these effects on women, an increasing number of studies now document the devastating effects on children of growing up in a family with domestic violence. In general, children who witness domestic violence exhibit problems in their social and emotional adjustment (e.g., Hughes, 1988; Hughes and Graham-Bermann, 1998; Sternberg et al., 1993). Researchers have documented increased levels of internalizing and externalizing behavior and decreased social competence (Jaffe et al., 1986), lower self-esteem (Hughes and Barad, 1983; Kolbo, 1996), increased behavior problems and psychopathology (Fantuzzo et al., 1991; Holden and Ritchie, 1991; Kolbo, 1996), increased fear and worry (Graham-Bermann, 1996), 
increased depression and aggression (McCloskey et al., 1995), and PTSD (Graham-Bermann and Levendosky, 1998; Lehmann, 1997; Rossman, 1994) in children of battered women.

The current study proposes and examines a model of the interrelated effects of domestic violence on women and children, focusing specifically on parenting. An integration of an ecological perspective and trauma theory is used to propose specific hypotheses about the mediating factors for the effects of domestic violence on women and children and to explain the processes involved in these effects. We theorized that parenting context (i.e., violence) impacts parenting behaviors (i.e., warmth, control, childcenteredness, and effectiveness) through its traumatic effects on the woman's psychological functioning. Consistent with Herman's trauma theory, trauma is conceptualized more broadly than the symptoms of posttraumatic stress disorder (APA, 1994) to include depression and anxiety. The child's psychological adjustment is hypothesized to be affected by all of these contextual variables, as well as by the direct experience of physical child abuse. A sample of women drawn primarily from the community is used to test this model. Thus, rather than grouping women by experience of violence, as was done in many previous studies, violence is examined as a continuous variable, and the severity of violence experienced by all of the women in the study is the risk factor.

Only a few studies have examined the effects of domestic violence on parenting and the effects of maternal parenting on children's adjustment in these families (Holden and Ritchie, 1991; Levendosky and GrahamBermann, 1998, in press; McCloskey et al., 1995; Wolfe et al., 1985). In general, these researchers report that psychological and physical abuse of women by their partners creates stress in parenting and negatively affects parenting behaviors.

However, these previous studies leave unanswered questions. For example, what are the determinants for parenting in a violent environment? How does the woman's parenting affect her child's adjustment? The potential damaging effects on parenting are another way in which batterers can harm their families, yet the existing literature on woman abuse often does not take the larger family system into account.

\section{AN ECOLOGICAL FRAMEWORK}

Belsky used an ecological framework to develop a model to understand the etiology of child maltreatment (Belsky, 1980) and eventually individual differences in parental functioning (Belsky, 1984). He drew upon 
Bronfenbrenner's model of the ecology of human development (Bronfenbrenner, 1977, 1979), which postulates a division of ecological space into micro-, exo-, and macrosystems. The microsystem involves what takes place in the immediate household, the exosystem involves the larger social system of the family, and the macrosystem involves relevant cultural beliefs and values. In addition, he integrated Burgess' concern (Burgess, 1978) about the ontogenic development (i.e., the individual differences of the parents' histories and personalities) into his original model (Belsky, 1980, 1984). This led to a new model of parental functioning, which included three general sources of influence: (1) the parents' own histories and psychological functioning, (2) the child's individual characteristics, and (3) contextual sources of support and stress (Belsky, 1984). Belsky proposed that contextual stress and support can influence parenting directly or indirectly through its effects on the parent's psychological functioning. In addition, these determinants of parenting were proposed to serve as buffers for the parent-child relationship in the context of stress. Thus, for our purposes, such an ecological model can be used to predict the factors that would influence parenting within the context of domestic violence.

\section{HYPOTHESES}

In this study, two conceptual models of the effects of domestic violence on parenting and children's adjustment were proposed to explain the variance in parenting and children's adjustment. The first is a simple direct effects model of domestic violence and child abuse on parenting and children's adjustment (see Fig. 1). We chose this approach because of its similarity to the models tested in the previous literature on the effects of domestic violence on children, that is, the direct effects of domestic violence on parenting and children's functioning. The second model integrates an ecological framework (Belsky, 1984) and Herman's trauma theory (Herman, 1992a,b) and uses factors from the ontogenic, micro-, and exosystem levels to construct a complex model of the role of parenting within the context of domestic violence (see Fig. 2). Herman's trauma theory was used to choose the particular environmental variables that would impact maternal psychological functioning within the context of domestic violence.

The primary hypothesis for this study is that the ecological model will demonstrate the importance of additional environmental variables in understanding the effects of domestic violence on women and children that cannot be tested in a simple direct effects model used by most of the previous research in this field. The secondary hypotheses for this study include 


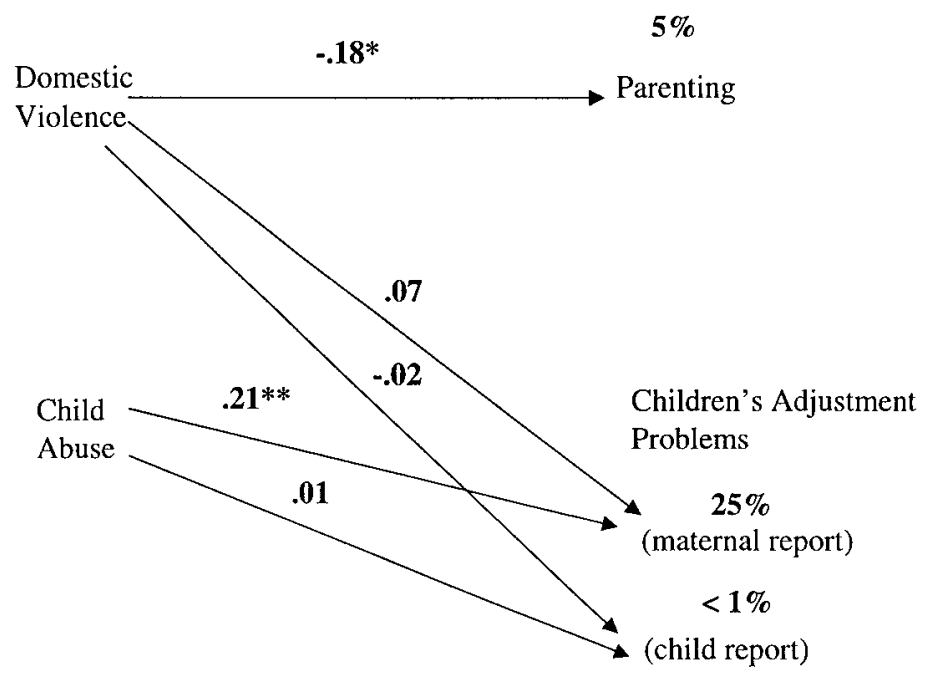

Goodness of Fit indices (maternal report)

$\mathrm{X}^{2} / \mathrm{df}=4.78 \mathrm{p}=.0025$

$\mathrm{GFI}=.93$ AGFI $=.78$

$\operatorname{RMSR}=.25$
Goodness of Fit indices (child report)

$\mathrm{X}^{2} / \mathrm{df}=3.18 \mathrm{p}=.023$

$\mathrm{GFI}=.96 \mathrm{AGFI}=.86$

RMSR $=.15$

Fig. 1. Direct effects model and results of parenting and children's adjustment in domestic violence families.

the particular relations between the variables in the ecological model. These hypotheses are indicated by the paths drawn in Fig. 2.

\section{METHOD}

\section{Participants}

The sample consisted of 120 women and one of their children residing in the community or in domestic violence shelters. The children were between $7-12$ years of age, with an average age of $9.6(S D=1.80)$ years. The mean family income was low, $\$ 977(S D=771)$ per month. There were 59 girls and 61 boys in the sample. Mother's average age was $34.03(S D=5.94)$ years. The mothers educational level range was as follows: $20 \%$ had less than a high school education, $23 \%$ had a high school degree, $38 \%$ had some college, and $19 \%$ had a college degree. The average family size was 3.31 children $(S D=$ 1.51). Fifty percent of the sample were White; $39 \%$ were African American; and the remaining $11 \%$ consisted of Latino, Arab American, and Indian American families. 


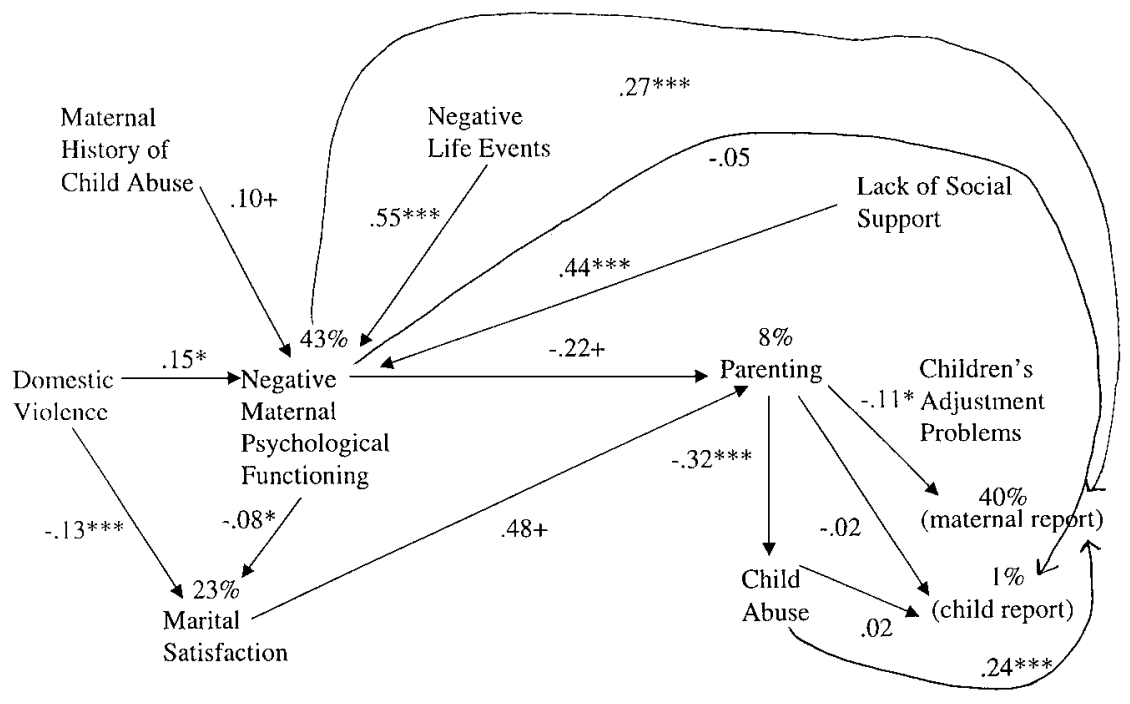

Goodness of Fit Indices (maternal report) $\mathrm{X}^{2} / \mathrm{df}=2.09 \mathrm{p}=.004$

$\mathrm{GFI}=.94 \quad \mathrm{AGFI}=.84$

$\mathrm{RMSR}=.08$
Goodness of Fit Indices (child report)

$\mathrm{X}^{2} / \mathrm{df}=1.84 \mathrm{p}=.02$

$\mathrm{GFI}=.94 \mathrm{AGFI}=.85$

RMSR $=.08$

Fig. 2. Ecological model and results of parenting and children's adjustment in domestic violence families.

The women were recruited in two urban Michigan communities through posters in apartment complexes, schools, churches, and grocery stores; through distribution of flyers in food stamp offices; newspaper advertisements; flyers at the YMCA after-care program; and flyers at domestic violence shelters and community support groups. The flyers advertised a study on family relationships for women with a child between 7-12 years of age.

The sample was specifically designed to include women with a range of abuse experiences because of perceived problems in previous studies of comparing women in shelters with women in the community, as described in the Introduction. In fact, the women ranged in their experience of domestic violence, from none at all to very frequent psychological and physical abuse within the last year (see Table I). Although a comparison of the 19 battered women recruited from the shelter with the rest of the sample revealed that they experienced significantly more psychological and physical abuse than the nonsheltered women $(p<.05)$, we considered them to be closer to the end of the continuum of violence, rather than a different group. 
Table I. The Violence Characteristics of the Entire Sample $(n=120)$

\begin{tabular}{lrrr}
\hline \multicolumn{1}{c}{ Violence characteristics } & Mean $(S D)$ & Min & Max \\
\hline Frequency of physical abuse (number of events per year) & $7.16(20.68)$ & 0 & 165 \\
Frequency of psychological abuse (number of events per year) & $21.12(40.64)$ & 0 & 258 \\
Length of current abusive relationship (in years) & $3.43(5.29)$ & 0 & 21 \\
Number of abusive partners & $1.46(1.95)$ & 0 & 20 \\
Total length of abusive relationships (in years) & $6.74(6.03)$ & 0 & 22 \\
Length of time since left the abusive relationship (in years) & $2.24(3.76)$ & 0 & 20 \\
& Yes & No \\
\cline { 2 - 4 } Maternal history of abuse with partners & 104 & 16 \\
Battered within the last year & 64 & 56 \\
History of child abuse of child subject & 70 & 50 \\
Physical abuse of child within the last year & 41 & 79 \\
Maternal history of child abuse & 80 & 40 \\
\hline
\end{tabular}

\section{Measures}

\section{Family Violence}

Conflict Tactics Scale (CTS; Straus, 1979). This measure, completed by mothers, was used to assess the amount of child abuse in the home perpetrated by the mother within the last year. The verbal aggression and physical violence scores were used. The reliability and validity of the CTS is high (Straus, 1979; Straus et al., 1980).

Domestic Violence. This was measured using the Conflict Tactics Scale (Straus, 1979) and the Violence Against Women Scales (Marshall, 1992). Both psychological abuse and physical abuse were computed for frequency of occurrence during the last year. Women were also asked about the length of their current abusive relationship and about the number and length of past abusive adult relationships. In this study, reliability for the two scales was high; alphas $=.89$ and .92 .

Maternal History of Child Abuse. This scale was a 13-item modified version of the Childhood Trauma Questionnaire (Bernstein et al., 1993). Each item was answered "yes" or "no," and a total score was computed for each woman by summing the number of "yes" responses. The reliability for this study was high; alpha $=.88$.

\section{Negative Maternal Psychological Functioning}

Beck Depression Inventory (BDI; Beck et al., 1961). The mothers completed this 21-item measure assessing the level of current depressive symptoms. The reliability and validity of this scale is high (Beck et al., 1961). In the current study, the internal reliability of this measure was alpha $=.92$. 
Brief Symptom Inventory (BSI; Derogatis and Melisaratos, 1983). The mothers completed this 53-item questionnaire assessing her current psychological symptoms, including insomnia, anxiety, and auditory hallucinations. The global severity index, computed by averaging all of the items, was used in this study. In the current study, the internal reliability coefficient was alpha $=.96$.

Posttraumatic Stress Scale for Family Violence (PTSD Scale; Saunders, 1994). The questions for this measure are based on the PTSD symptoms from the DSM III-R(APA, 1987). The total number of PTSD symptoms reported was used as the score from this measure. The internal reliability coefficient for this study was .95 . Saunders (1994) found a .94 reliability coefficient and a correlation of $r=.58$ with other PTSD scales.

\section{Marital Satisfaction}

The mothers completed the 37-item Dyadic Adjustment Scale (DAS; Spanier, 1976) assessing satisfaction with their current or most recent partner. The measure has high validity and reliability (Spanier and Thompson, 1982). In this study, the internal reliability coefficient was alpha $=.93$.

\section{Negative Life Events}

The 19-item Life Stress Scale (Abidin, 1990) was used to assess the number of negative life events that have occurred in the family within the last year. Each event that had occurred in her immediate family within the last year was rated on how stressful it was from 1 to 5 . The internal reliability coefficient was alpha $=.53$.

\section{Lack of Social Support}

Social Support Quality of Life Scale (Solarz, 1987). This scale assessed both the subject's perception of quantity of support, as well as quality of support, including companionship, advice and information, practical support, and emotional support. Scores were reversed so that high scores indicated low satisfaction with social supports. In this study, the internal consistency reliability for quality of support was .77, and for quantity of support was .74.

Parenting Stress Index (PSI; Abidin, 1990). The subscale assessing the woman's sense of social isolation was used in this study. In the current study, the internal reliability coefficient was alpha $=.69$. 


\section{Parenting}

Parenting Style Survey (PSS; Sameroff et al., 1990). This 62-item scale was used as a self-report index of the woman's parenting style. The subscales of warmth, control, child-centeredness, and effectiveness were used in this study. The internal consistency reliabilities were as follows: warmth .65 , control .57, child-centeredness .51, and effectiveness .66.

\section{Children's Adjustment}

Child Behavior Checklist (CBCL; Achenbach and Edelbrock, 1986). Mothers were asked to complete this 118-item questionnaire measuring children's emotional and behavioral problems. The two broadband subscales, internalizing and externalizing behaviors, were used in this study. This measure has high reliability and validity (Achenbach, 1991). In this study, the internal reliabilities were high: alphas $=.90,97$.

Children's Depression Inventory (CDI; Kovacs, 1985). This 27-item self-report measure evaluated the extent of depression in the child in the last 2 weeks. High reliability and validity of the CDI have been established (e.g. Kazdin et al., 1985; Kovacs, 1985). In this study, the internal consistency was alpha $=.86$.

Perceived Competence Scales for Children (Harter, 1985). The 6-item subscales of social competence and global self-worth were used. Moderate reliability and validity have been established (Harter, 1982). In this study, the reliabilities were alphas $=63,68$.

\section{Procedure}

The women and children from the community were interviewed in a university setting. Because of the rules at one of the shelters, the women and children at this shelter were interviewed at the shelter in two staff offices. The interviews of the mothers generally lasted between 2 and $3 \mathrm{hr}$, whereas the child interviews lasted between 1.5 and $2 \mathrm{hr}$. All questionnaires were read aloud to the participants. Child care was provided for the children not involved in the interviews. The interviewers were trained graduate and advanced undergraduate students in psychology. Before the interviews began, the women signed informed consent for themselves and their children. Children were verbally asked to give their assent to answer questions about themselves and their families. The women were paid $\$ 30$ for their participation, and the children received a small age-appropriate gift. If the child was 
reported by the mother to have been abused in the last year and no report had been filed at Child Protective Services (CPS), then such a report was filed by the project investigator. Five new cases were reported to CPS over the course of this study.

\section{Data Reduction}

For the purposes of testing the models (see Figs. 1 and 2), it was necessary to reduce the data so that the number of cases per parameter estimated was 8-10 (Bentler and Chou, 1987). Although there is some controversy in the field over the number of participants used in structural equation modeling (SEM), Bollen (1989) suggests that there be at least several participants per free parameter. Others suggest that there should be at least 200 participants for SEM analyses (Chou and Bentler, 1995). Reducing the data in this study allowed 10 participants for each parameter estimated. In order to do this, a variable was computed for each construct in the models by adding the standardized variables to make a composite score. For example, maternal psychological functioning was computed by adding the woman's standardized scores on the BDI, the BSI, and the PTSD scale. Each individual variable was weighted a 1.0 in making the construct, rather than weighting variables differently (Liang et al., 1988). Table II lists the alpha reliabilities and variables for each of the composite scores.

\section{RESULTS}

\section{Correlations Between Demographic Variables and Variables in the Models}

There were no significant associations between the demographic variables and the composite variables used in the models. Thus, the demographic variables were not included in the model analyses.

\section{Structural Equation Modelling}

Structural equation path models were used to examine the empirical credibility of the two proposed theoretical models. Maximum likelihood estimates of the path coefficients were obtained using LISREL 8 (Joreskog and Sorbom, 1989). As previously described, instead of using latent-variable analysis, each construct was computed apriori (Liang et al., 1988). Table III contains the correlations for all constructs used in testing the model. Because 
Table II. Alpha Reliabilities for Composite Variables and Means and Standard Deviations for Individual Variables

\begin{tabular}{|c|c|c|c|c|}
\hline Construct & $\begin{array}{l}\text { Composite } \\
\text { alpha }\end{array}$ & Variables & Mean & $\begin{array}{l}\text { Standard } \\
\text { deviation }\end{array}$ \\
\hline \multirow[t]{4}{*}{ Domestic violence } & .72 & $\begin{array}{l}\text { Frequency of physical } \\
\text { abuse }\end{array}$ & 7.16 & 20.68 \\
\hline & & $\begin{array}{l}\text { Frequency of } \\
\text { psychological abuse }\end{array}$ & 21.12 & 40.64 \\
\hline & & $\begin{array}{l}\text { Length of current abusive } \\
\text { relationship }\end{array}$ & 3.43 & 5.29 \\
\hline & & $\begin{array}{l}\text { Total length of abusive } \\
\text { partner relationships }\end{array}$ & 6.74 & 6.03 \\
\hline \multirow[t]{2}{*}{ Child abuse } & .72 & $\begin{array}{l}\text { Mother to child verbal } \\
\text { aggression }\end{array}$ & 2.07 & 1.55 \\
\hline & & $\begin{array}{l}\text { Mother to child physical } \\
\text { aggression }\end{array}$ & 1.12 & 0.82 \\
\hline \multirow{4}{*}{$\begin{array}{l}\text { Negative maternal } \\
\text { psychological functioning }\end{array}$} & & & & \\
\hline & .75 & Depression & 12.88 & 10.31 \\
\hline & & Global symptoms & 0.96 & 0.70 \\
\hline & & Total PTSD symptoms & 8.88 & 6.25 \\
\hline \multirow[t]{3}{*}{ Lack of social supports } & .77 & Social isolation & 14.93 & 4.46 \\
\hline & & Low quality of supports & 3.46 & 1.23 \\
\hline & & Low quantity of supports & 3.61 & 1.19 \\
\hline \multirow[t]{4}{*}{ Parenting } & .65 & Warmth & 3.62 & 0.33 \\
\hline & & Control & 2.83 & 0.61 \\
\hline & & Effectiveness & 3.29 & 0.58 \\
\hline & & Child-centeredness & 3.23 & 0.30 \\
\hline Negative life events & NA & Negative life events & 3.68 & 2.42 \\
\hline Marital satisfaction & NA & Marital satisfaction & 73.07 & 25.74 \\
\hline $\begin{array}{l}\text { Maternal history of child } \\
\text { abuse }\end{array}$ & NA & $\begin{array}{l}\text { Maternal history of child } \\
\text { abuse }\end{array}$ & 2.78 & 3.01 \\
\hline \multirow{2}{*}{$\begin{array}{l}\text { Maternal report of } \\
\text { children's adjustment }\end{array}$} & & Internalizing behaviors & 12.20 & 9.47 \\
\hline & & Externalizing behaviors & 15.71 & 10.99 \\
\hline \multirow{3}{*}{$\begin{array}{l}\text { Children's self-reports of } \\
\text { adjustment }\end{array}$} & & Depression & 8.17 & 7.26 \\
\hline & & Social competence & 2.88 & 0.68 \\
\hline & & Global self-worth & 3.29 & 0.61 \\
\hline
\end{tabular}

of the low correlations between the mother and child reports of the child adjustment measures, the models were analyzed separately for mother and child report of child adjustment outcome.

Several goodness-of-fit indices were used to evaluate the models, including the ratio between chi-square and its degrees of freedom $\left(\chi^{2} / d f\right.$; Carmines and McIver, 1981), measures of the relative amounts of variances and covariances jointly accounted for in the model (GFI and AGFI; Joreskog and Sorebom, 1989), and root mean square residuals (RMSR; Joreskog and Sorebom, 1989).

In Model 1, the direct effects of domestic violence and child abuse on parenting and maternal report of children's adjustment accounted for $5 \%$ of 
Table III. Correlations Between the Constructs Used in the Structural Equation Models.

\begin{tabular}{|c|c|c|c|c|c|c|c|c|c|c|}
\hline & 1 & 2 & 3 & 4 & 5 & 6 & 7 & 8 & 9 & 10 \\
\hline 1. Parenting & - & & & & & & & & & \\
\hline $\begin{array}{l}\text { 2. Maternal report of } \\
\text { child adjustment }\end{array}$ & $-.37^{* *}$ & - & & & & & & & & \\
\hline $\begin{array}{l}\text { 3. Children's report of } \\
\text { child adjustment }\end{array}$ & .02 & .01 & - & & & & & & & \\
\hline $\begin{array}{l}\text { 4. Negative maternal } \\
\text { psychological functioning }\end{array}$ & $-.23^{*}$ & $.52^{* *}$ & -.02 & - & & & & & & \\
\hline 5. Marital satisfaction & $.23^{* *}$ & $-.35^{* *}$ & -.005 & $-.32^{* *}$ & - & & & & & \\
\hline 6. Negative life events & -.13 & $.28^{* *}$ & .03 & $.46^{* *}$ & -.12 & - & & & & \\
\hline $\begin{array}{l}\text { 7. Lack of social } \\
\text { support }\end{array}$ & $-.26^{* *}$ & $.24^{* *}$ & .12 & $.56^{* *}$ & $-.32^{* *}$ & $.31^{* *}$ & - & & & \\
\hline $\begin{array}{l}\text { 8. Maternal history } \\
\text { of child abuse }\end{array}$ & -.04 & $.24^{* *}$ & .08 & $.22^{*}$ & -.17 & .08 & .17 & - & & \\
\hline 9. Child abuse & $-.31^{* *}$ & $.53^{* *}$ & .02 & $.30^{* *}$ & $-.29^{* *}$ & .12 & .14 & $.21^{*}$ & - & \\
\hline 10. Domestic violence & -.18 & .16 & -.02 & $.32^{* *}$ & $-.44^{* *}$ & $.30^{* *}$ & .12 & .08 & .15 & - \\
\hline
\end{tabular}

Note: ${ }^{*} p<.05,{ }^{* *} p<.01$

the variance in parenting, and $25 \%$ of the variance in child adjustment (see Fig. 1). Child abuse was the only significant predictor of children's adjustment. Domestic violence was a significant predictor of parenting. Evidence for the fit of the model was not adequate, with a significant chi-square, a chi-square/degrees of freedom of 4.78, a GFI of .93, an AGFI of .78, and a RMSR of .25

In Model 1, the direct effects of domestic violence and child abuse on parenting and children's report of children's adjustment accounted for $5 \%$ of the variance in parenting and less than $1 \%$ of the variance in child adjustment (see Fig. 1). The only significant pathway in this model was the effect of domestic violence on parenting. Evidence for the fit of the model was marginally adequate, with a significant chi-square, a chi-square/degrees of freedom of 3.2, a GFI of .96, an AGFI of .86, and a RMSR of .15.

Model 2, with ecological effects on parenting and maternal report of children's adjustment, accounted for $8 \%$ of the variance in parenting, and $40 \%$ of the variance in children's adjustment (see Fig. 2). In addition, it accounted for $43 \%$ of the variance in negative maternal psychological functioning, $23 \%$ of the variance in maternal marital satisfaction, and $11 \%$ of the variance in child abuse. Domestic violence was a significant predictor of negative maternal psychological functioning and marital satisfaction. Maternal childhood history of abuse, lack of social support, and negative life events were all significant predictors of maternal psychological functioning. Negative maternal psychological functioning was a significant predictor of marital satisfaction. There was a marginally significant association between negative maternal 
psychological functioning and marital satisfaction in predicting parenting. Negative maternal psychological functioning and parenting were both significant predictors of children's adjustment. Parenting also was a significant predictor of child abuse. Finally, child abuse was a significant predictor of children's adjustment. Evidence for the fit of the ecological model was modest, with a significant chi-square, a chi-square/degrees of freedom of 2.1, a GFI of .94, an AGFI of .84, and a RMSR of .08.

Model 2 with ecological effects on parenting and children's report of children's adjustment accounted for less than $1 \%$ of the variance in children's adjustment (see Fig. 2). The rest of the model was identical to the model using maternal report of children's functioning, except as follows: parenting, negative maternal psychological functioning, and child abuse did not significantly predict children's adjustment. Evidence for the fit of the ecological model was good, with a significant chi-square, a chi-square/degrees of freedom of 1.8, a GFI of .95, an AGFI of .85, and a RMSR of .08.

In sum, although the models can not be directly compared statistically because they are not nested models, conceptually, a comparison demonstrates the greater power of an ecological model in understanding the various environmental factors that influence functioning in these families compared with the direct effects model.

\section{DISCUSSION}

Overall, these results indicate that models that only take into account the direct effects of domestic violence on parenting or children's adjustment or both are missing important environmental factors that help to understand the individual differences in functioning between women and children in these circumstances. The ecological model in this study fit the data well and indicated that there were significant associations between variables that would be suggested by the use of trauma theory. Thus, we conclude that this study supports this ecologically based model of the effects of domestic violence on women and children. In addition, we conclude that the results support a trauma theory explanation for the processes through which domestic violence affects women and children. Finally, the findings suggest that research designs comparing battered women or their children to a nonviolent group to examine the effects of violence are insufficient to account for the numerous potential mediators between violence and children's adjustment. The following discussion is organized into sections based on the ecological model: ontogenic factors, microsystem factors, and exosystem factors. 


\section{Ontogenic Factors}

\section{Maternal Psychological Functioning}

Lower psychological functioning was related to poorer parenting in this study. Prior studies documented deleterious effects of depression on parenting (Rogosh et al., 1992; Rutter, 1990; Sameroff et al., 1982). These links between parental psychological health and parenting differences are consistent with Belsky's process model (Belsky, 1984) of the determinants of parenting.

In the ecological model, the mother's psychological functioning had its own direct effects on children, that were not solely mediated through its effects on her parenting. Perhaps even if the mother is able to maintain adequate parenting, the changes in her affect and mood could have deleterious effects on her children's emotional well-being. For example, the child may worry more about the mother. Our result supports other findings of direct effects of maternal depression on children's adjustment (Beardslee et al., 1987). In addition, trauma survivors may have wide variation in their functioning (Janoff-Bulman, 1992; van der Kolk, 1987) and the parenting style questionnaire may have been less sensitive to these variations than the measures of psychological symptoms. Perhaps the children respond more to their mother's variability in functioning, rather than to her overall style of parenting. If the woman has been battered for a long time, and has suffered depression for much of this time, it may be that the children were unable to form a secure attachment with their mother and so regardless of her parenting style in later years, the children's adjustment was affected by the lack of a secure attachment (Ainsworth, 1985; Egeland et al., 1983).

\section{Maternal Childhood History of Abuse}

There was a marginally significant relation between higher maternal childhood history of abuse and worse maternal psychological functioning. This lends some support to Walker's argument (Walker, 1983) that women's history of child abuse is another risk factor in women's psychological reactions to the domestic violence. Consistent with trauma theory, this finding indicates that the women who have already been traumatized as children may carry this vulnerability into their adult lives. 


\section{Microsystem Factors on Mother and Child}

\section{Domestic Violence}

The effects of domestic violence on parenting are mediated through its effects on the woman's negative psychological functioning and marital satisfaction. Prior studies of domestic violence also found that these women reported more depression and trauma symptoms, and felt more dissatisfied with their relationships (Cascardi and O'Leary, 1992; Dutton and Painter, 1993; Khan et al., 1993; Saunders, 1994). In addition, the theoretical literature hypothesizes that battered women are traumatized by the violence they experience from their partner (Herman, 1992b; Janoff-Bulman, 1992).

Frequency and chronicity of domestic violence and negative maternal psychological functioning were significantly related to marital satisfaction and accounted for $23 \%$ of its variance. Other studies found that depression is related to lower marital satisfaction and warmth (Beach and O'Leary, 1993; Burns et al., 1994; O'Leary et al., 1994). Researchers have found lower marital satisfaction in battered women, although these studies did not measure chronicity or frequency of psychological abuse (Jouriles et al., 1989; Sato and Heiby, 1992).

\section{Child Abuse}

In contrast to other studies of children who witnessed domestic violence and children who were abused (Sternberg et al., 1993), this study showed that child abuse (rather than witnessing violence) was the more important predictor of children's adjustment in Model 1. This finding is consistent with some of the literature on trauma in child abuse survivors versus witnesses (Rossman et al., 1993).

\section{Marital Satisfaction}

Marital satisfaction had a marginally significant association with parenting in this study. The meta-analysis by Erel and Burman (1995) found that marital conflict and distress were significantly and negatively linked to parenting. Although this study did not support such a strong relation, it is possible that the context of domestic violence was a more significant factor than in the studies reviewed by Erel and Burman, which focus on nonviolent marital conflict and distress. 


\section{Parenting Qualities}

Parenting qualities played a significant role in the adjustment of children in this study, a finding consistent with the literature on parenting (e.g., Baumrind, 1967). There was both a direct effect from parenting and an effect mediated through child abuse. The finding that parenting is related to children's adjustment in domestic violence families is consistent with findings for parenting in other high-risk environments, such as poverty and unemployment (Conger et al., 1992, 1993; McLoyd, 1990).

\section{Exosystem Factors}

Lack of social support and negative life events each were related to women's psychological functioning. Therefore, part of the differing psychological reactions in battered women may be explained through their experience of social support systems in their environment, including family, friends, and social service agencies, as well as their experience of recent difficult experiences. These results are consistent with Belsky's (1984) ecological framework of the determinants of parenting.

Negative life events have been shown in previous research to negatively affect psychological functioning, including depression and posttraumatic stress symptoms (Fondacaro and Moos, 1989; McMahon et al., 1993; Strickland, 1992). The effects of additional negative life events may be particularly salient for battered women who are already dealing with trauma at home. One trauma theorist, Janoff-Bulman (1992), argued that after trauma, social support serves to help a woman regain a sense of trust in her environment. This finding carries significance for treatment strategies. Given that battered women are commonly isolated by their abusive partner, it is clear that increasing their social support system may be an important point of intervention (Walker, 1978). Although consistent with trauma theory, the reason why having less perceived social support is associated with more negative psychological functioning is still unclear. It may be that fewer social supports cause women to feel more depressed or it may be that depression causes women to withdraw, or it may be that violent men force their partners to withdraw socially, or all three. It would be important to untangle the causal relationship between lack of social support and psychological functioning in future studies.

\section{LIMITATIONS}

One limitation was that the findings suggest a possible alternative interpretation based on single-reporter bias. Perhaps women who were more 
depressed and traumatized responded to the questionnaires in a depressed response style, viewing themselves as less happily married, possessing poorer parenting qualities, and having children with more behavior problems. It is possible that this is an accurate reflection of reality, but it is also possible that it is a depressed view of reality. Because the children did not rate themselves in a manner consistent with the maternal ratings, it is an interpretation that cannot be dismissed. In fact, researchers have consistently found poor correlations between parent and child reports of child symptomatology and have hypothesized that this is because of their different experiences of the child's emotional and behavioral functioning (Achenbach, 1991; Routh, 1990).

The measure of parenting style may have been a limitation as well, as it captures overall parenting qualities, as rated by the mother, but does not seem sensitive to the variability in parenting that is probably present in trauma survivors. The oscillation between hyperarousal and numbing is likely to cause great variability in parenting style. Thus, observations of parent-child interaction may be the best solution to examine the specific impact of trauma on parenting.

Finally, a problem with the conceptualization of this study is the focus only on women's parenting in these families. Fathers or stepfathers also parent the children in these families and their parenting surely has an impact on the children's adjustment. The missing paternal parenting variables may account for some of the unexplained variance in children's adjustment. However, the inclusion of the fathers in a study about domestic violence is always risky because they may not be willing to have their family examined if they have knowledge of the nature of the study or the questions about family violence. The presence of the father may also inhibit the woman or the child in responding to the questions.

\section{CONCLUSIONS}

The findings in this study emphasize the need to help battered women's psychological functioning and parenting, including reducing child abuse, in order to make the maximum impact on the children in these families. We now know that children are affected by the domestic violence through the impact that the batterer has on their mother, as well as through any direct abuse perpetrated on them by either parent.

Lack of social support played a significant role in the woman's negative psychological functioning. This is a particularly important finding in that many women in battering relationships have few social supports due to the controlling aspect of the battering relationship. Clearly, women who feel that they have social support networks are less depressed and traumatized. This 
argues for the importance of the availability of support groups for women who are suffering from domestic violence, or who have suffered in the past. In addition, the development of neighborhood support networks may also be helpful for these women.

There are several important improvements in this study over many others in the field of domestic violence research. This study did not limit the sample of battered women to those in a shelter, so that it is more generalizable to the broader population of battered women. The sample itself was more ecologically valid than many previous samples, as it included women from a broader range of socioeconomic status, income, education, and ethnic groups. Psychological and physical abuse were both measured as aspects of domestic violence and were considered to be on a continuous scale, rather than present or absent. This allowed for examination of the impact of increasing domestic violence on women and children. Finally, the use of an ecological framework to test the risk factors for parenting and children's adjustment in violent families is a more complex way of understanding the effects of domestic violence. Integration of this model and trauma theory thus adds significantly to our understanding of the processes through which violence affects women and children.

\section{ACKNOWLEDGMENTS}

This study was funded by a Rackham Dissertation Grant from the University of Michigan to Alytia A. Levendosky. We thank the following colleagues for their helpful comments and suggestions: Jacquelynne Eccles, Michael Lambert, Joel Nigg, Arnold Sameroff, and Daniel Saunders. Alexander Von Eye and Laura Klem were invaluable in assisting with the LISREL analyses. We would like to thank the following students who assisted in this project: Michelle Byrd, Julie Crews, Maureen Feldman, Stacey Gallagher, Shoma Ghose, Angie Kirchner, Shannon Lynch, Iran Naqvi, Santhi Periasamy, and Kristin Piehl.

\section{REFERENCES}

Abidin, R. (1990). Parenting Stress Index, 3rd Edition: Test Manual, Pediatric Psychology Press, Charlottesville, VA.

Achenbach, T. M. (1991). Manual for the Child Behavior Checklist/4-18 and 1991 Profile. University of Vermont, Department of Psychiatry, Burlington, VT.

Achenbach, T. M., and Edelbrock, C. S. (1986). Child Behavior Checklist and Youth Self-Report, Author, Burlington, VT.

Ainsworth, M. D. (1985). Patterns of attachment. Clin.Psychol. 38: 27-29. 
American Psychiatric Association (1987). Diagnostic and Statistical Manual of Mental Disorders-III-Revised, APA, Washington, DC.

American Psychiatric Association (1994). Diagnostic and Statistical Manual of Mental Disorders- $I V$, APA, Washington, DC.

Baumrind, D. (1967). Child care practices anteceding 3 patterns of preschool behavior. Gen. Psychol. Monogr. 75: 43-88.

Beach, S. R., and O'Leary, K. D. (1993). Dysphoria and marital discord: Are dysphoric individuals at risk for marital maladjustment? J. Marital Fam. Ther. 19: 355-368.

Beardslee, W., Schultz, L., and Selman, R. (1987). Level of social cognitive development, adaptive functioning, and DSM-III diagnoses in adolescent offspring of parents with affective disorders: Implications of the development of the capacity for mutuality. Dev Psychol. 23: 807-815.

Beck, A. T., Ward, C. H., Mendelson, M., Mock, J., and Erbaugh, J. (1961). An inventory for measuring depression. Arch. Gen. Psychiatry 4: 561-571.

Belsky, J. (1980). Child maltreatment: An ecological integration. Am. Psychol. 35: 320-335.

Belsky, J. (1984). The determinants of parenting: A process model. Child Dev. 55: 83-96.

Bentler, P. M. and Chou, C. P. (1987). Practical issues in structural modelling. Sociolog. Meth. Res. 16: 78-117.

Bernstein, D. P., Fink, L., Handelsman, L., Foote, J., Lovejoy, M., and Ruggiero, J. (1993). Toward a New Measure of Childhood Trauma: The CTQ, VA Medical Center, Bronx, NY, and Mt. Sinai School of Medicine, New York, NY.

Bollen, K. A. (1989). Structural Equations With Latent Variables, John Wiley and Sons, New York.

Bronfenbrenner, U. (1977). Toward an experimental ecology of human development. Am. Psychol. 32: 513-531.

Bronfenbrenner, U. (1979). The Ecology of Human Development, Harvard University Press, Cambridge, MA.

Burgess, R. (1978). Child abuse: A behavioral analysis. In Lakey, B. and Kazdin, A. (eds.), Advances in Child Clinical Psychology, Plenum Press, New York.

Burns, D. D., Sayers, S. L., and Moras, K. (1994). Intimate relationships and depression: Is there a causal connection? J. Consult. Clin. Psychol. 62: 1033-1043.

Campbell, J. C., Kub, J., Belknap, R. A., and Templin, T. N. (1997). Predictors of depression in battered women. Violence Against Women 3(3): 271-293.

Carmines, E. G., and McIver, J. P. (1981). Analyzing models with unobserved variables: Analysis of covariance structures. In Borhnstedt, G. W., and Borgatta, E. F. (eds.), Social Measurement: Current Issues, Sage, Beverly Hills, CA.

Cascardi, M., and O'Leary, K. D. (1992). Depressive symptomatology, self-esteem, and selfblame in battered women. J. Fam. Violence 7: 249-259.

Chou, C.-P., and Bentler, P. M. (1995). Estimates and tests in structural equation modeling. In Hoyle, R. H. (ed.), Structual Equation Modeling: Concepts, Issues, and Applications, Sage, Thousand Oaks, CA.

Conger, R. D., Conger, K. J., Elder, G. H., Lorenz, F. O., Simons, R. L., and Whitbeck, L. B. (1992). A family process model of economic hardship and adjustment of early adolescent boys. Child Dev. 63: 526-541.

Conger, R. D., Conger, K. J., Elder, G. H., Lorenz, F. O., Simons, R. L., and Whitbeck, L. B. (1993). Family economic stress and adjustment of early adolescent girls. Dev. Psychol. 29: 206-219.

Derogatis, L., and Melisaratos, N. (1983). The Brief Symptom Inventory: An introductory report. Psychol. Med. 13: 595-605.

Dutton, D. G., and Painter, S. (1993). The battered woman syndrome: Effects of severity and intermittency of abuse. Am. J. Orthopsychiatry 63: 614-622.

Egeland, B., Sroufe, L. A., and Erickson, M. F. (1983). Developmental consequence of different patterns of maltreatment. Child Abuse Negl. 7: 459-469.

Erel, O., and Burman, B. (1995). Interrelatedness of marital relations and parent-child relations: A meta-analytic review. Psychol. Bull. 118: 108-132. 
Fantuzzo, J. W., DePaola, L. M., Lambert, L., Martino, T., Anderson, G., and Sutton, S. (1991). Effects of interparental violence on the psychological adjustment and competence of young children. J. Clin. Consult. Psychol. 59: 258-265.

Fondacaro, M. R., and Moos, R. H. (1989). Life stressors and coping: A longitudinal analysis among depressed and nondepressed adults. J. Community Psychol. 17: 330-340.

Graham-Bermann, S. A. (1996). Family worries: The assessment of interpersonal anxiety in children from violent and nonviolent families. J. Clin. Child Psychol. 25: 280-287.

Graham-Bermann, S. A., and Levendosky, A. A. (1998). Traumatic stress symptoms in children of battered women. J. Interpersonal Violence 14: 111-128.

Harter, S. (1982). The perceived competence scale for children. Child Dev. 53: 87-97.

Harter, S. (1985). Manual for the Self-Perception Profile for Children, University of Denver, Denver.

Herman, J. L. (1992a). Complex PTSD: A syndrome in survivors of prolonged and repeated trauma. J. Trauma. Stress 5: 377-391.

Herman, J. L. (1992b). Trauma and Recovery, Basic Books, New York.

Holden, G. W., and Ritchie, K. L. (1991). Linking extreme marital discord, child rearing, and child behavior problems: Evidence from battered women. Child Dev. 62: 311-327.

Houskamp, B. M., and Foy, D. W. (1991). The assessment of posttraumatic stress disorder in battered women. J. Interpersonal Violence 6: 367-375.

Hughes, H. M. (1988). Psychological and behavioral correlates of family violence in child witnesses and victims. Am. J. Orthopsychiatry 58: 77-90.

Hughes, H. M., and Barad, S. J. (1983). Psychological functioning of children in a battered women's shelter: A preliminary investigation. Am. J. Orthopsychiatry 53: 525-531.

Hughes, H. M., and Graham-Bermann, S. A. (1998). Children of battered women: Impact of emotional abuse on adjustment and development. J. Emo. Ab. 1:23-50.

Jaffe, P., Wolfe, D., Wilson, S., and Zak, L. (1986). Family violence and child adjustment: A comparative analysis of girls' and boys' behavioral symptoms. Am. J. Psychiatry 143: $74-77$.

Janoff-Bulman, R. (1992). Shattered Assumptions: Toward a New Psychology of Trauma, The Free Press, New York.

Joreskog, K. G., and Sorbom, D. (1989). LISREL VII: User's Reference Guide, 1st Ed., Scientific Software, Mooresville, IN.

Jouriles, E. N., Murphy, C. M., and O’Leary, K. D. (1989). Interspousal aggression, marital discord, and child problems. J. Consul. Clin. Psychol. 57, 453-455.

Kazdin, A. E., Moser, J., Colbus, D., and Bell, R. (1985). Depressive symptoms among physically abused and psychiatrically disturbed children. J. Abnorm. Child Psychol. 11: 401-413.

Kemp, A., Green, B. L., Hovanitz, C., and Rawlings, E. I. (1995). Incidence and correlates of posttraumatic stress disorder in battered women. J. Interpersonal Violence 10: 43-55.

Kemp, A., Rawlings, E. I., and Green, B. L. (1991). Post-traumatic stress disorder (PTSD) in battered women: A shelter sample. J. Trauma. Stress 4: 137-148.

Khan, F. I., Welch, T. L., and Zillmer, E. A. (1993). MMPI-2 profiles of battered women in transition. J. Pers. Assess. 60: 100-111.

Kolbo, J. R. (1996). Risk and resilience among children exposed to family violence. Violence and Vict. 11(2): 113-128.

Kovacs, M. (1985). The Children's Depression Inventory (CDI). Psychopharmacol. Bull. 21: 995-999.

Lehmann, P. (1997). The development of posttraumatic stress disorder (PTSD) in a sample of child witnesses to mother assault. J. Fam. Violence 12(3): 241-257.

Lempers, J. D., Clark-Lempers, D., and Simon, K. L. (1989). Economic hardship, parenting and distress in adolescence. Child Dev. 60: 25-39.

Levendosky, A. A., and Graham-Bermann, S. A. (1998). The moderating effects of parenting stress on children's adjustment in woman-abusing families. J. Interpersonal Violence 12(3): 383-397.

Levendosky, A. A., and Graham-Bermann, S. A. (2000). Behavioral observations of parenting in battered women. J. Fam. Psychol. 14: 1-15. 
Liang, J., Tran, T. V., and Markides, K. S. (1988). Differences in the structure of Life Satisfaction Index in three generations of Mexican Americans. J. Gerontol. 43: S1-S8.

Marshall, L. (1992). Development of the severity of violence against women scales. J. Fam. Violence 7: 103-121.

McCloskey, L. A., Figueredo, A. J., and Koss, M. P. (1995). The effects of systemic family violence on children's mental health. Child Dev. 66: 1239-1261.

McLoyd, V. C. (1990). The impact of economic hardship on Black families and children: Psychological distress, parenting, and socioemotional development. Child Dev. 61: 311346.

McMahon, R. C., Schram, L. L., and Davidson, R. S. (1993). Negative life events, social support, and depression in three personality types. J. Pers. Disorders 7: 241-254.

O'Leary, K. D., Christian, J. L., and Mendell, N. R. (1994). A closer look at the link between marital discord and depressive symptomatology. J. Soc. and Clin. Psychol. 13: 33-41.

Rogosh, R. A., Mowbray, C. T., and Bogat, G. A. (1992). Determinants of parenting attitudes in mothers with severe psychopathology. Dev. Psychopathol. 4: 460-487.

Rossman, B. B. R. (1994). Children in violent families: Diagnostic and treatment considerations. Fam. Viol. Sex. Ass. Bull. 10: 29-34.

Rossman, B. B. R., Bingham, R. D., Dickerson, L. K., Cimbora, D. M., Dexter, R. M., and Balog, S. A. (1993). Trauma symptoms in child witnesses to parental violence. Presented at the Society for Research in Child Development, New Orleans, LA.

Rounsaville, B. J., and Lifton, N. (1983). A therapy group for battered women. In Rosenbaum, M. (ed.). Handbook of Short-Term Therapy Groups, McGraw-Hill, New York, pp. 155-179.

Routh, D. K. (1990). Taxonomy in developmental psychopathology: Consider the source. In Lewis, M., and Miller, S. M. (eds.), Handbook of Developmental Psychopathology, Plenum Press, New York.

Rutter, M. (1990). The developmental psychopathology of depression: Issues and perspectives. In Rolf, J., Masten, A. S., Cicchetti, D., Nuechterlein, K. N., and Weintraub, S. (eds.), Risk and Protective Factors in the Development of Psychopathology, Cambridge University Press, Cambridge.

Sameroff, A. J., Seifer, R., and Zax, M. (1982). Early development of children at risk for emotional disorder.Monogr. Soc. Res. Child Dev. 47(7, Serial No. 199).

Sameroff, A. J., Thomas, S. L., and Barrett, L. C. (1990). Anxiety and parental childrearing styles. Presented at the Society for Research in Adolescence.

Sato, R. A., and Heiby, E. M. (1992). Correlates of depressive symptoms among battered women. J. Fam. Violence 7: 229-245.

Saunders, D. G. (1994). Post-traumatic stress symptoms profiles of battered women: A comparison of survivors in two settings. Violence Vict. 9: 31-44.

Solarz, A. L. (1987). Follow-up study in a temporary shelter for the homeless: A look at quality of life and social supports. Diss. Abstr. Int. 47(12-B, Pt 1): 5044.

Spanier, G. B. (1976). Measuring dyadic adjustment : New seales for assessing the quality of marriage and similar dyads. J. Marr. Fam. 38: 15-28.

Spanier, G. B., and Thompson, L. (1982). A confirmatory analysis of the dyadic adjustment scale. J. Marr. Fam. 44: 731-738.

Sternberg, K. J., Lamb, M. E., Greenbaum, C., Cicchetti, D., Dawud, S., Cortes, R. A., Krispin, O., and Lorey, F. (1993). Effects of domestic violence on children's behavior problems and depression. Dev. Psychol. 29: 44-52.

Straus, M. A. (1979). Measuring intrafamily conflict and violence: The Conflict Tactics (CT) Scales. J. Marr. Fam. 41: 75-88.

Straus, M. A., Gelles, R. J., and Steinmetz, S. K. (1980). Behind Closed Doors: Violence in the American Family, Anchor Press, Garden City, NJ.

Strickland, B. R. (1992). Women and depression. Curr. Dir. Psychol. Sci. 1: 132-135.

Testa, M., Miller, B. A., and Downs, W R. (1993). Women's self-esteem predicts subsequent violent victimization by partner. Presented at the American Psychological Association conference, Toronto, Canada.

van der Kolk, B. A. (1987). Psychological Trauma, APA, Washington, DC. 
Vitanza, S., Vogel, L. C. M., Maeshall, L. L. (1995). Distress and symptoms of posttraumatic stress disorder in abused women. Violence. Vict. 10(1): 23-34.

Walker, L. E. (1978). Battered women and learned helplessness. Victimology 2: 525-534.

Walker, L. E. (1983). The battered women syndrome study. In Finkelhor, D., Gelles, R. J., Hotaling, G. T. and Straus, M. A. (eds.), The Dark Side of Families: Current Family Violence Research, Sage, Beverly Hills, CA.

Wolfe, D. A., Jaffe, P., Wilson, S. K., and Zak, L. (1985). Children of battered women: The relation of child behavior to family violence and maternal stress. J. Consult. Clin. Psychol. 53(5): 657-665. 